\title{
Experimental Prediction of Helical Coil Heat Exchanger
}

\author{
Dharmesh L. Umaraniya* and P. A. Deshmukh \\ Rajarshi Shahu College of Engineering, Tathawade,SP Pune University, Mumbai, India \\ Accepted 15 June 2016, Available online 20 June 2016, Special Issue-5 (June 2016)
}

\begin{abstract}
Enhancements of heat transfer in helically coil have researched by many researchers. So many literatures are available on characteristics of heat transfer coefficient on helically coils. Basically this paper focus on experiment prediction of fluid heat transfer enhancement of varying pitch of helical coil. The technique of experiment investigation of a helical coils tubes heat exchanger, the effect of the annulus tubes at steady value of mass flow rate in Reynolds and Dean Number and as well established the surface of coefficient of heat transfer. While taking various boundary conditions on inside tube helical coils for finding characteristics of heat transfer. Hence, considering different mass flow inside and outside of helically coil heat exchanger. The fabrication of experimental setup is estimate the heat transfer enhancement in inside helical coil tubes.
\end{abstract}

Keywords: Helical Coil Tubes Heat Exchanger, Coil Configuration, Flow Parameters (Parallel and Counter), Dean Number.

\section{Introduction}

Heat exchanger is a device which is used to transfer heat between two fluids which may be in direct contact or may flow separately in two tubes or channels. We find numerous applications of heat exchangers in day today life. For example condensers and evaporators used in refrigerators and air conditioners. In thermal power plant heat exchangers are used in boilers, condensers, air coolers and chilling towers etc. Similarly the heat exchangers used in automobile industries are in the form of radiators and oil coolers in engines. Heat exchangers are also used in large scale in chemical and process industries for transferring the heat between two fluids which are at a single or two states.

Working towards the goal of saving energies and to make compact the design for mechanical and chemical devices and plants, the enhancement of heat transfer is one of the key factors in design of heat exchangers.

Helical coils are very alluring for many processes in heat exchanger and reactors because of it accommodate higher heat transfer rate in small space. The fluid motion in curved pipe was observed by Eustice in 1911.Since then numerous studies have been reported on the flow fields that arise in curved pipes (Dean, White, Hawthorne, Horlock, Barua, Austin and Seader) including double pipe helical coils, which is a subset of curved. Jayakumar et alwas investigated in helical coil tubes at numerous process parameters.

*Corresponding author: Dharmesh L. Umaraniya
Mohamed A. Abd Raboh et al. carried out on experimental work for condensation overall heat transfer inside double pipe helical coil. Pablo Coronel et al have been made known on the helically coiled heat exchanger is higher than that in straight tubular heat exchanger. Rahul Kharat et al determine the heat transfer coefficient correlation for concentric helical coil tubes heat exchanger. Ashok Reddy et. al.studies on the effect of dean number over heat transfer coefficient in an agitated vessel. Timoty et al worked on experimental studies of double pipe heat exchanger

\section{Problem Formulation}

In the literature review, found that so many worked has been done to enhancement of the heat transfer coefficient in heat exchanger. But there is no work has been done to optimize the heat transfer rate with respect to Geometrical specification. In this paper work, I optimize the given helical coil heat exchanger keeping in mind that it should produce maximum heat transfer rate with variation of specification Because some times in the process of improving the heat transfer coefficient.

\subsection{Problem Specification}

In my study I consider the double tube helical coil heat exchanger or tube in tube helical coil heat exchanger with two different pitches. For simplification in experimental analysis I consider. 


\subsection{Helical coil geometry and parameters}

The geometry of the helical tube is as follows, Experimental Setup is shown in Fig.1; The bottom radius of curvature is denoted (R), the pipe diameter (a), the helical pitch as (P), the straight height (h) and For a straight helical coil the height (h) will be equal to the height of the coil (I) will change in accordance to that angle, while keeping (h) constant.
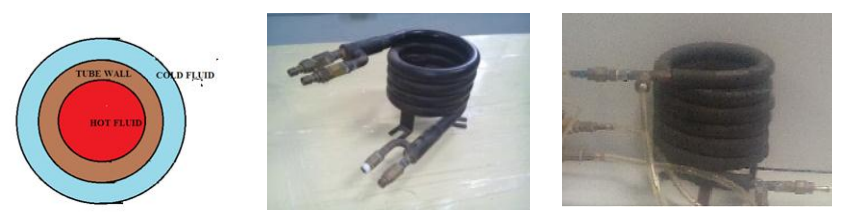

Figure1: Front view of helical coil heat exchanger showing different helical coil

Table 1 Coil Dimension Parameter

\begin{tabular}{|c|c|c|}
\hline S. No. & Dimensional Parameters & Dimension \\
\hline 1 & Inner Coil Diameter & $16 \mathrm{~mm}$ \\
\hline 2 & Outer Coil Diameter & $25.4 \mathrm{~mm}$ \\
\hline 3 & Pipe Thickness & $1 \mathrm{~mm}$ \\
\hline 4 & Tube Pitch & $\begin{array}{c}35 \mathrm{~mm} \text { and } 40 \\
\mathrm{~mm}\end{array}$ \\
\hline 5 & Pitch Circle Diameter & $200 \mathrm{~mm}$ \\
\hline
\end{tabular}

After manufacturing helical coil tubes and doing the experiments on their setup the problem was analyzed, for different boundary conditions as specified later. For analysis of the problem was to be taken in laminar flow fluid flow condition was considered.

\subsection{Formulation}

In this experimental work heat transfer coefficients and heat transfer rates were based on the measured on temperature data.

The overall heat transfer coefficient, $\mathrm{U}_{0}$,

$U_{o}=\frac{q}{A_{o} T_{L M T D}}$

Hot Water Heat transfer Rate

$Q_{h}=\left(m_{h, f} x C_{p} x\left(T_{h, i}-T_{h, o}\right)\right)$

Cold Water Heat transfer Rate,

$Q_{c}=\left(m_{c, f} x C_{p} x\left(T_{c, o}-T_{c, i}\right)\right)$

Mean Heat Transfer Rate, $Q_{\text {mean }}=\frac{Q_{h}+Q_{c}}{2}$

The physical properties of water are taken at average temperature; $T_{\text {mean }}=\frac{T_{i}+T_{o}}{2}$

LMTD is the log mean temperature difference, based on the inlet temperature difference, $\left(\Delta T_{1}\right)$, and the outlet temperature difference, $\left(\Delta T_{2}\right)$, using the following equation (White, 1984):

For Parallel flows Condition:
$T_{L M T D}=\frac{\left(\Delta T_{1}\right)-\left(\Delta T_{2}\right)}{\ln \left(\frac{\Delta T_{1}}{\Delta T_{2}}\right)}=\frac{\left(T_{h, i}-T_{c, i}\right)-\left(T_{h, o}-T_{C, o}\right)}{\ln \left(\frac{T_{h, i}-T_{C, i}}{T_{h, o}-T_{C, o}}\right)}$

For Counter-flow Condition:

$T_{L M T D}=\frac{\left(\Delta T_{1}\right)-\left(\Delta T_{2}\right)}{\ln \left(\frac{\Delta T_{1}}{\Delta T_{2}}\right)}=\frac{\left(T_{h, i}-T_{C, o}\right)-\left(T_{h, o}-T_{c, i}\right)}{\ln \left(\frac{T_{h, i}-T_{c, o}}{T_{h, o}-T_{c, i}}\right)}$

Reynolds number (Re); $R e=\frac{\rho v d}{\mu}$

For Dean Number; $D e=R e \sqrt{\frac{d_{i}}{D_{h}}}$

Where di is inner tubes diameter, Dh is Helix diameter.

\section{Experimental Procedure}

Flow rates in the annulus and in the inner tube were varied. The following four levels were used: 0.0028, $0.0056,0.0084$ and $0.0112 \mathrm{~kg} / \mathrm{sec}$. All possible combinations of these flow rates in both the inner and annulus tube were tested. Testing is to be done for both coils configuration, and under both flow condition like parallel flow and counter-flow configurations.

Furthermore, every combination of flow rate is to be done under three replicates, coil size and configuration. This resulted in a total of 150 trials. Every ten seconds, temperature data was recorded, after the system had stabilized. Temperature measurements from the 60 seconds of the stable system were used, with temperature reading fluctuations within $+/-0.1^{\circ} \mathrm{C}$. Though the type-K (error of $2.2^{\circ} \mathrm{C}$ ) thermocouples had limits, when placed in a common water solution the readings at steady state were all. All the thermocouples were constructed from the same roll of thermocouple wire, and hence the repeatability of temperature readings was high.

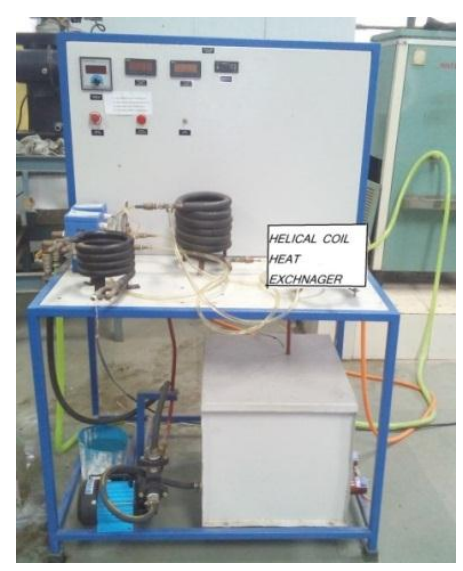

Figure: 2 Experimental Setup

\section{Results and Discussion}

In Figure 3, figure 4, figure 5 and figure 6 are presented Overall heat transfer coefficients (OHTC) for parallel and counter flow for the two different pitch helical coil 
heat exchanger results. The overall heat transfer coefficient (OHTC) is drawing the graph against the inner Dean number $\left(N_{D e}\right)$ for all flow rates of the annulus. A fluid-to-fluid helically coils heat exchanger with overall heat transfer coefficient(OHTC) increases in inner as well as annulus flow rates. Figure shows that in the annulus and inner flow rate, increasing the overall heat transfer coefficient of the helically coils in high pitch coil. This figure is define the value of overall heat transfer rate with increasing the Inner dean number, the experimental results we can see in table no.-02, table no.-04. Table no-02 and 04 is denoted the parallel flow condition of $35 \mathrm{~mm}$ and $40 \mathrm{~mm}$ pitch and table no.-03 and table no.-05 are denoted the counter flow condition of the $30 \mathrm{~mm}$ and $40 \mathrm{~mm}$ pitch of the helical coil heat exchanger.

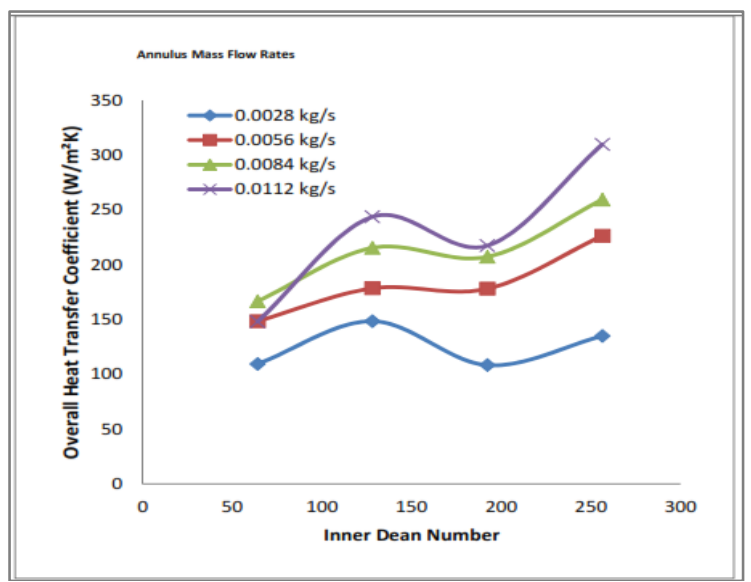

Figure: 3 Overall heat transfer coefficient (OHTC) versus the inner Dean number $\left(N_{D e}\right)$ for the small pitch $(35 \mathrm{~mm})$ of each annulus mass flow rate in parallel flow.

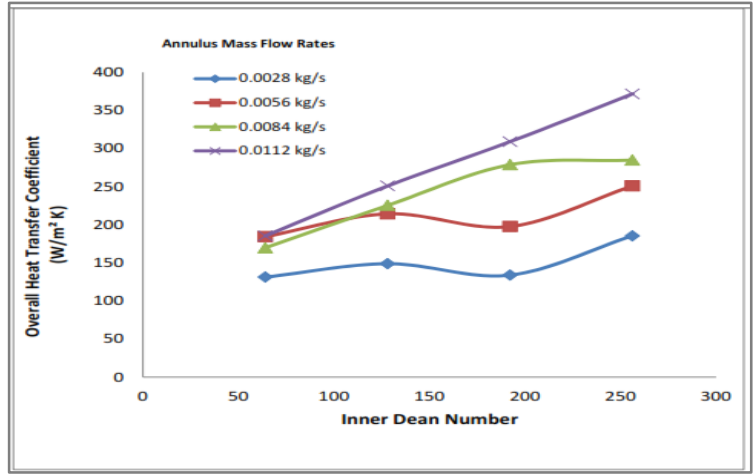

Figure: 4 Overall heat transfer coefficient (OHTC) versus the inner Dean number $\left(N_{D e}\right)$ for the large pitch $(40 \mathrm{~mm})$ of each annulus mass flow rate in parallel flow.

The results come from the experiments to shows that the value of counter-flow configuration has similar to the parallel flow configuration, as is expected, if changing the flow configuration should have negligible effect on the overall heat transfer coefficients. Due to the increased LMTD, heat transfer rates, are much higher in the counter-flow configuration.

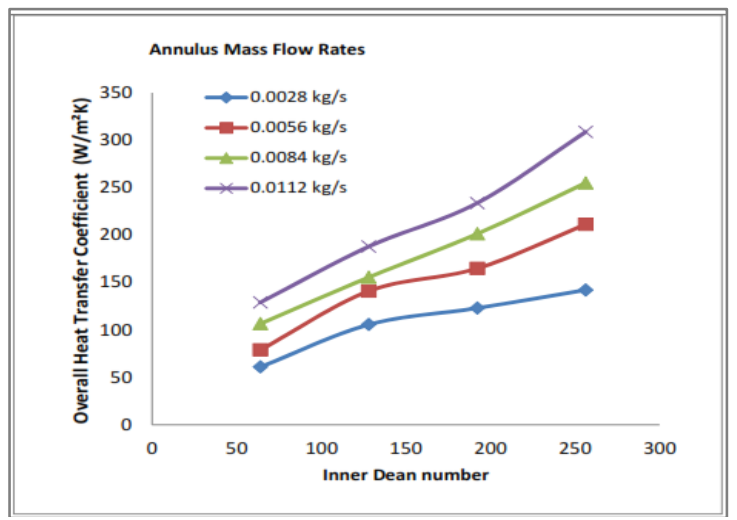

Figure: 5 Overall heat transfer coefficient (OHTC) versus the inner Dean number $\left(N_{D e}\right)$ for the large pitch $(35 \mathrm{~mm})$ of each annulus mass flow rate in Counter flow

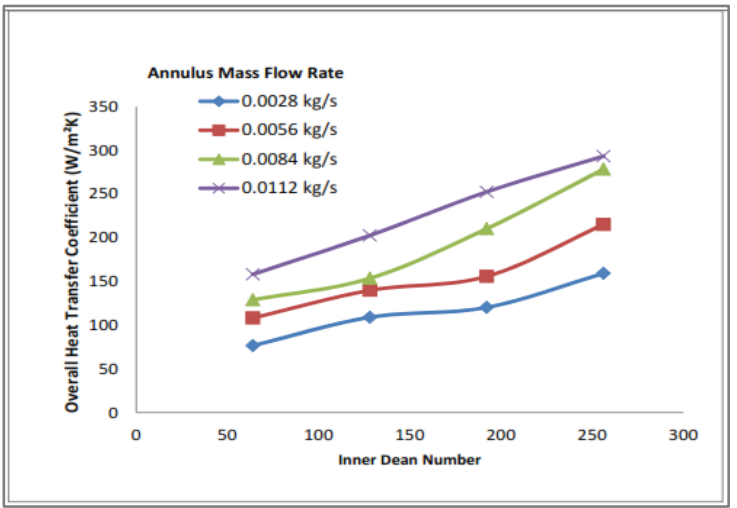

Figure: 6 Overall heat transfer coefficient versus the inner Dean number for the large pitch (40 $\mathrm{mm})$ of each annulus mass flow rate in Counter flow

From figure-7 and figure-8, has to be plotted graph between counter flow verses the parallel flow overal heat transfer coefficients, where the values plotted against each other are from the same experimental parameters. There is a reasonable agreement between the two values.

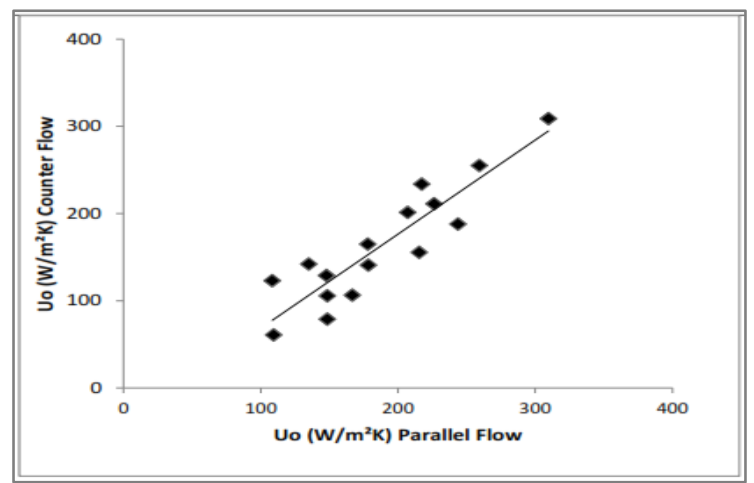

Figure: 7 Graph between counter flow verses the parallel flow 


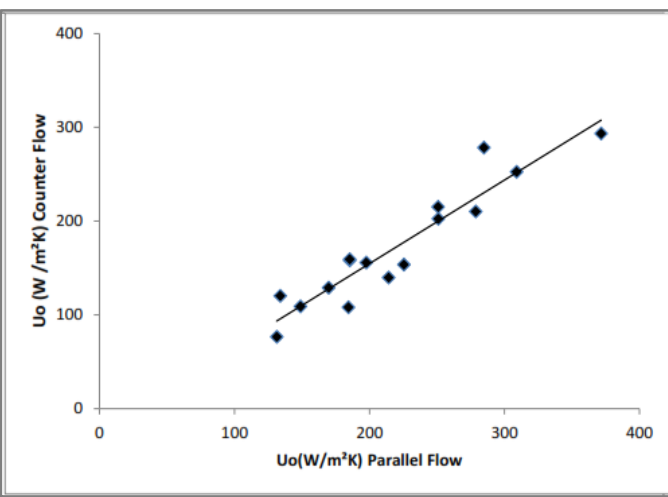

Figure 8: Counter flow overall heat transfer coefficient (OHTC)versus parallel flow overall heat transfer coefficient(OHTC) for all trails. ( Pitch $=40 \mathrm{~mm}$ )

The inner Nusselt numbers are presented in Figure 9 and figure 10 (with \pm 2 standard errors). These values are the inner Nusselt number at each Dean number (parallel flow and counter-flow values).

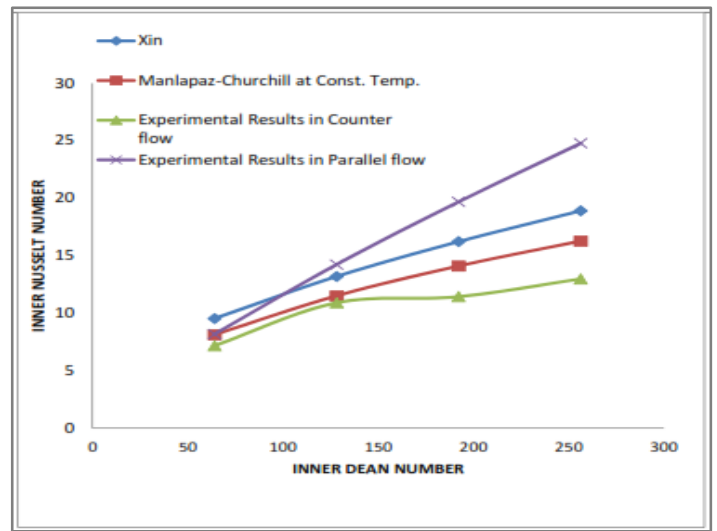

Figure: 9. Nusselt Number( $\mathrm{Nu})$ verses Inner Dean Number $\left(N_{D e}\right)$ of small coil Pitch (Parallel and Counter Flow)

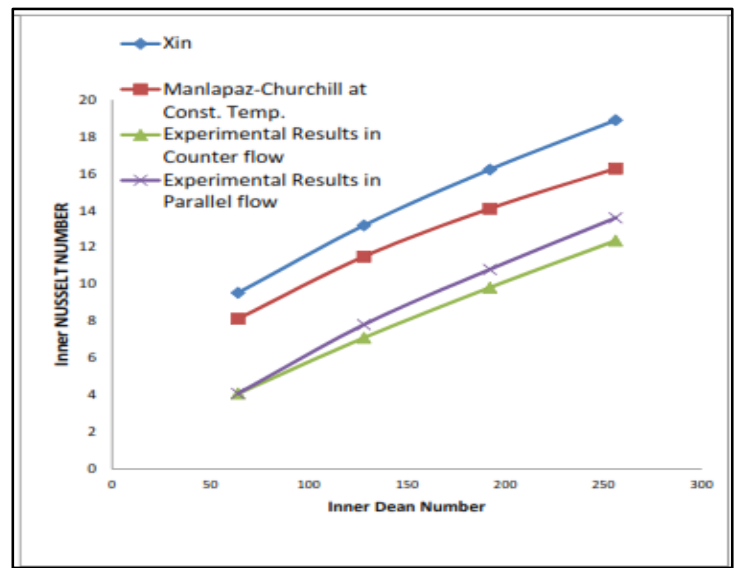

Figure:10 Nusselt Number( $\mathrm{Nu})$ verses Inner Dean Number $\left(N_{D e}\right)$ of Large coil Pitch (Parallel and Counter Flow)

\section{Conclusions}

An experimental study of a double pipe helically heat exchanger was performed using two differently sized pitch heat exchangers. The mass flow rates in the inner tube and in the annulus were both varied, as well as both parallel flow and c o u n t e r-flow configurations were tested.

There were little differences between the overall heat transfer coefficients for the parallel flow and counter-flow configurations.

However, heat transfer rates were much higher in the counter-flow configuration due to the larger average temperature difference between the two fluids.

In table- 2 and table -4 have shown the parallel flow condition, very slightly differences in both pitch condition of the helical coil heat exchanger. But in case of counter flow condition in both pitch differences have more as comparing to parallel flow conditions.

The Nusselt number in the inner tube was compared to the Manlapaz- Churchill correlation (1981), Xin and M. R. Salimpour, small coil pitch and large coil pitch values, further work needs to be done to quantify this effect.

\section{References}

Rahul Kharat, Nitin Bhardwaj, R.S. Jha Development of heat transfer coefficient correlation for concentric helical coil heat exchangerInternational Journal of Thermal Sciences 48 (2009) 23002308

J.S. Jayakumar, S.M. Mahajani, J.C. Mandal, Experimental and CFD estimation of heat transfer in helically coiled heat exchangers, Chemical engineering research and design, Vol. 86, (2008), pp. 221 232.

Kapil Dev, Kuldeep Singh Pal, Suhail A. Siddiqui , An Empirical Study of Helical Coil Heat Exchanger Used in Liquid Evaporization and Droplet Disengagement for a Laminar Fluid Flow International Journal of Engineering Sciences \& Research Technology April, 2014, ISSN: 2277. 9655

Pablo Coronel, K.P. Sandeep Heat Transfer Coefficient in Helical Heat Exchangers under Turbulent Flow Conditions International Journal of Food Engineering, Volume 4, Issue 12008 Article 4.

Timothy J. Rennie, Vijaya G.S. Raghavan, Experimental studies of a doublepipe helical heat exchanger, IOSR January 2005.

B. Chinna Ankanna, B. Sidda Reddy, Performance analysis of fabricated helical coil heat exchanger. International Journal of Engineering Research ISSN:2319-6890)(online),2347-5013 Volume No.3 Issue No: Special 1, pp: 33-39 22nd March 2014

Pramod S. Purandarea, Mandar M. Leleb, Rajkumar Gupta Parametric analysis of helical coil heat exchanger. International Journal of Engineering Research \& Technology (IJERT),ISSN: 2278-0181,Vol. 1 Issue 8, October - 2012

Ashok Reddy K, Bhagvanth Rao M. Ram Reddy. Effect of dean number on heating transfer coefficients in an flat bottom agitated vessel. IOSR Journal of Engineering May. 2012, Vol. 2(5) pp: 945-951.

H. S. Patel, R.N.Makadia, A review on performance evaluation and cfd analysis of double pipe heat exchanger. PARIPEX - Indian Journal O Research. Volume : 2 | Issue : 4 | April 2013 ISSN - 2250-1991.

Alok Vyas, Mr. Prashant Sharma, An Experimental Analysis Study to Improve Performance of Tubular Heat Exchangers. Journal of Engineering Research and Applications www.ijera.com ISSN : 22489622, Vol. 3, Issue 6, Nov-Dec 2013, pp.1804-1809.

S. Laohlertdecha,A.S. Dalkilic and S. Wongwises, A Review on the heat transfer equipments and pressure-drop characteristics of various enhanced tubes International Journal of Air-Conditioning and Refrigeration Vol. 20, No. 4 (2012) 1230003 (20 pages) .

Pardeep Kumar,Vijay Kumar,Sunil Nain Experimental Study on Heat Enhancement of Helix-changer with Grooved Tubes. International Journal of Latest Trends in Engineering and Technology (IJLTET) Vol. 3 Issue 4 March 2014 ISSN: 2278-621X. 


\section{Appendix}

Table 2 Experimental results in Parallel flow of Pitch = $35 \mathrm{~mm}$

\begin{tabular}{|c|c|c|c|c|}
\hline $\boldsymbol{m} \boldsymbol{h}(\mathbf{k g} / \mathbf{s})$ & $\boldsymbol{m c}(\mathbf{k g} / \mathbf{s})$ & $\boldsymbol{L M T D}$ & $\boldsymbol{Q a v .}(\boldsymbol{W})$ & $\boldsymbol{U}(\boldsymbol{W})$ \\
\hline 0.0028 & 0.0028 & 11.166649 & 245.9016 & 109.3442566 \\
\hline & 0.0056 & 11.166649 & 333.7236 & 148.3957768 \\
\hline & 0.0084 & 11.166649 & 374.7072 & 166.6198195 \\
\hline & 0.0112 & 13.363524 & 398.1264 & 147.9304028 \\
\hline 0.0056 & 0.0028 & 11.166649 & 333.7236 & 148.3957768 \\
\hline & 0.0056 & 13.363524 & 480.0936 & 178.3866622 \\
\hline & 0.0084 & 13.363524 & 579.6252 & 215.3692629 \\
\hline & 0.0112 & 13.363524 & 655.7376 & 243.6500752 \\
\hline 0.0084 & 0.0028 & 15.022979 & 327.8688 & 108.3681135 \\
\hline & 0.0056 & 15.022979 & 538.6416 & 178.0333293 \\
\hline & 0.0084 & 16.421704 & 685.0116 & 207.127217 \\
\hline & 0.0112 & 17.659944 & 772.8336 & 217.2972072 \\
\hline 0.0112 & 0.0028 & 13.363524 & 362.9976 & 134.8777202 \\
\hline & 0.0056 & 13.363524 & 608.8992 & 226.2464984 \\
\hline & 0.0084 & 15.022979 & 784.5432 & 259.3094145 \\
\hline & 0.0112 & 15.022979 & 936.768 & 309.6231814 \\
\hline & & & & \\
\hline
\end{tabular}

Table 3 Experimental results Counter flow of Pitch = $35 \mathrm{~mm}$

\begin{tabular}{|c|c|c|c|c|}
\hline $\boldsymbol{m h}(\mathbf{k g} / \mathbf{s})$ & $\boldsymbol{m c}(\mathbf{k g} / \mathbf{s})$ & LMTD & Qav. $(\boldsymbol{K W})$ & $\boldsymbol{U}(\boldsymbol{K W})$ \\
\hline 0.0028 & 0.0028 & 20.9841174 & 257.6112 & 60.9739206 \\
\hline & 0.0056 & 18.7550355 & 345.4332 & 78.86187033 \\
\hline & 0.0084 & 18.1952605 & 433.2552 & 106.5396575 \\
\hline & 0.0112 & 17.4422544 & 491.8032 & 128.985105 \\
\hline 0.0056 & 0.0028 & 18.7159013 & 398.1264 & 105.6526312 \\
\hline & 0.0056 & 19.39269 & 550.3512 & 140.9522292 \\
\hline & 0.0084 & 19.9983152 & 626.4636 & 155.5867183 \\
\hline & 0.0112 & 18.5681758 & 702.576 & 187.9291533 \\
\hline 0.0084 & 0.0028 & 18.1952605 & 450.8196 & 123.0593446 \\
\hline & 0.0056 & 19.9331546 & 661.5924 & 164.8483328 \\
\hline & 0.0084 & 19.9331546 & 807.9624 & 201.3192029 \\
\hline & 0.0112 & 19.1547945 & 901.6392 & 233.7897012 \\
\hline 0.0112 & 0.0028 & 16.9798632 & 485.9484 & 142.14319 \\
\hline & 0.0056 & 18.7159013 & 796.2528 & 211.3052624 \\
\hline & 0.0084 & 18.929616 & 971.8968 & 255.0048469 \\
\hline & 0.0112 & 18.4593881 & 1147.5408 & 308.7599208 \\
\hline
\end{tabular}

Table 4 Experimental results in Parallel flow of Pitch = $40 \mathrm{~mm}$

\begin{tabular}{|c|c|c|c|c|}
\hline $\mathrm{Mh}(\mathrm{kg} / \mathrm{s})$ & $\mathrm{Mc}(\mathrm{kg} / \mathrm{s})$ & Lmtd & Qav. $(\mathrm{w})$ & $\mathrm{U}(\mathrm{w})$ \\
\hline 0.0028 & 0.0028 & 11.167 & 245.902 & 131.2471 \\
\hline & 0.0056 & 11.167 & 345.433 & 184.371 \\
\hline & 0.0084 & 13.364 & 380.562 & 169.7289 \\
\hline & 0.0112 & 13.364 & 415.691 & 185.3962 \\
\hline 0.0056 & 0.0028 & 13.364 & 333.724 & 148.8392 \\
\hline & 0.0056 & 13.364 & 480.094 & 214.1195 \\
\hline & 0.0084 & 15.023 & 567.916 & 225.3093 \\
\hline & 0.0112 & 15.023 & 632.318 & 250.8598 \\
\hline 0.0084 & 0.0028 & 16.422 & 368.852 & 133.8708 \\
\hline & 0.0056 & 16.422 & 544.496 & 197.6187 \\
\hline & 0.0084 & 15.023 & 702.576 & 278.7331 \\
\hline & 0.0112 & 15.023 & 778.688 & 308.9292 \\
\hline 0.0112 & 0.0028 & 13.364 & 415.691 & 185.3962 \\
\hline & 0.0056 & 15.023 & 632.318 & 250.8598 \\
\hline & 0.0084 & 16.422 & 784.543 & 284.741 \\
\hline & 0.0112 & 15.023 & 936.768 & 371.6442 \\
\hline
\end{tabular}

Table 5 Experimental results Counter flow of Pitch = $40 \mathrm{~mm}$

\begin{tabular}{|c|c|c|c|c|}
\hline $\begin{array}{c}\mathrm{Mh} \\
(\mathrm{kg} / \mathrm{s})\end{array}$ & Mc(kg/s) & Lmtd & Qav.(w) & $\mathrm{U}(\mathrm{w})$ \\
\hline 0.0028 & 0.0028 & 20.49593431 & 263.466 & 76.61400937 \\
\hline & 0.0056 & 19.99831516 & 362.9976 & 108.1836621 \\
\hline & 0.0084 & 18.13148967 & 392.2716 & 128.9450613 \\
\hline & 0.0112 & 16.76773081 & 444.9648 & 158.1621997 \\
\hline 0.0056 & 0.0028 & 20.16639053 & 368.8524 & 109.012368 \\
\hline & 0.0056 & 21.46507088 & 503.5128 & 139.8071947 \\
\hline & 0.0084 & 22.04447843 & 567.9156 & 153.5448673 \\
\hline & 0.0112 & 19.64442002 & 667.4472 & 202.5018696 \\
\hline 0.0084 & 0.0028 & 20.5976476 & 415.6908 & 120.2829643 \\
\hline & 0.0056 & 22.40710059 & 585.48 & 155.7319542 \\
\hline & 0.0084 & 21.4027489 & 755.2692 & 210.3214422 \\
\hline & 0.0112 & 20.59699077 & 872.3652 & 252.4328621 \\
\hline 0.0112 & 0.0028 & 17.31234049 & 462.5292 & 159.2335962 \\
\hline & 0.0056 & 19.79355214 & 714.2856 & 215.0797329 \\
\hline & 0.0084 & 19.93315462 & 930.9132 & 278.3456805 \\
\hline & 0.0112 & 20.93635363 & 1030.4448 & 293.3425209 \\
\hline
\end{tabular}

